\title{
HAS GLOBALIZATION TRANSFORMED U.S. MACROECONOMIC DYNAMICS?
}

\author{
FABIO MILANI
}

University of CALifornia, Irvine

\begin{abstract}
This paper estimates a structural New Keynesian model to test whether globalization has changed the behavior of U.S. macroeconomic variables. Several key coefficients in the model - such as the slopes of the Phillips and IS curves, the sensitivities of domestic inflation and output to "global" output, and so forth - are allowed in the estimation to depend on the extent of globalization (modeled as the changing degree of openness to trade of the economy), and, therefore, they become time-varying.

The empirical results indicate that globalization can explain only a small part of the reduction in the slope of the Phillips curve. The sensitivity of U.S. inflation to global measures of output may have increased over the sample, but it remains very small. The changes in the IS curve caused by globalization are similarly modest. Globalization does not seem to have led to an attenuation in the effects of monetary policy shocks.

The nested closed economy specification still appears to provide a substantially better fit of U.S. data than various open economy specifications with time-varying degrees of openness. Some time variation in the model coefficients over the post-war sample exists, particularly in the volatilities of the shocks, but it is unlikely to be related to globalization.
\end{abstract}

Keywords: Globalization and Inflation, Global Slack, Openness, New Keynesian model, Expectations and Adaptive Learning, DSGE model with Time-Varying Coefficients. JEL classification: E31, E50, E52, E58, F41.

Date: June, 2009.

Address for correspondence: Department of Economics, 3151 Social Science Plaza, University of California, Irvine, CA 92697-5100. Phone: 949-824-4519. Fax: 949-824-2182. E-mail: fmilani@uci.edu. Homepage: http://www.socsci.uci.edu/ fmilani. 


\section{INTRODUCTION}

The last fifty years have been characterized by a steady process of global economic integration. The U.S. economy has also become increasingly more open over the post-war period, at a pace that has further intensified since 1990. This process of globalization may have led to important changes in the behavior of some of the major U.S. macroeconomic variables, such as output, inflation, and interest rates. ${ }^{1}$ While the joint determination of these variables is still often studied within frameworks that treat the U.S. as a closed economy, there is a growing view that, in a globalized world, the old closed-economy models may have become inadequate (e.g., Fisher, 2006).

Some have already argued, for example, that traditional closed-economy Phillips curves may be an outdated representation of inflation behavior. Globalization may have altered the Phillips curve by changing its slope (e.g., Romer, 1993, and Rogoff, 2003, theorize that the curve should become steeper in a more open economy, while Binyamini and Razin, 2007, analytically show in a New Keynesian model that globalization flattens the Phillips curve) and, in particular, by causing inflation to be a function of global excess capacity, rather than exclusively a function of domestic capacity (e.g., Borio and Filardo, 2007, provide empirical evidence in favor of the so-called "global slack hypothesis"). Other commentators worry that globalization may impair the ability of domestic monetary policies to control inflation, at least in the short to medium-run (e.g., BIS, 2006, Fisher, 2005, and Rogoff, 2007, discuss some of the challenges that globalization poses to traditional monetary policy-making). ${ }^{2}$

This paper aims to investigate in a general equilibrium model the implications of the increasing globalization on the dynamics of U.S. macro variables, as output, inflation, and interest rates. The paper presents an estimation of a small-scale open-economy New Keynesian model, in which globalization is allowed to affect the relationships among variables. Globalization is

\footnotetext{
${ }^{1}$ Economists have already shown how globalization had a large impact in other contexts, for example, by contributing to the rising trend in U.S. wage inequality that began around 1980 (e.g., Feenstra and Hanson, 1996).

${ }^{2}$ The previous claims, however, remain controversial. Ihrig et al. (2007), for example, challenge Borio and Filardo's conclusions and find that measures of global output gap are not a relevant determinant of inflation. The papers by Tootell (1998), Gamber and Hung (2001), Wynne and Kersting (2007), Ball (2006), Castelnuovo (2007), and Milani (2009a,c) also contribute to this empirical debate. Woodford (2007) disputes, instead, the argument that globalization makes monetary policy less powerful and shows in a theoretical model that even in an open economy, national central banks retain their influence on economic activity and inflation. Boivin and Giannoni (2007) provide empirical evidence using an estimated factor-augmented VAR: they conclude that global forces did not lessen the effectiveness of monetary policy.
} 
intended in the paper as the degree of openness to trade in the economy, and expressed as the percentage of imports as a fraction of GDP, which, in the data, is changing and increasing over the sample.

Several coefficients in the model are allowed to vary depending on the degree of openness. First, globalization may alter the Phillips curve: it can change its slope, it can make the domestic inflation rate a function of the global output gap, and it can affect the formation of inflation expectations (which in the model will be near-rational, as agents will be assumed to learn about the structure of the economy over time). Second, globalization may affect the domestic IS curve, by modifying the sensitivity of output to domestic real interest rates and to expected changes in foreign output. These reduced-form sensitivities are functions of the structural coefficients and are all directly influenced by the time-varying degree of openness in the economy, which more than quadruples over the sample. One of the main focuses of the estimation will be to reveal to what extent these key reduced-form coefficients have evolved over time as a function of globalization.

In addition to its influence on the determination of output and inflation, globalization may also affect monetary policy. The link between globalization and monetary policy has been studied by a number of authors. Romer (1993) and Rogoff (2003) use a Barro-Gordon framework to illustrate how globalization reduces the incentive for central banks to create unanticipated inflation; Loungani and Razin (2005) and Binyamini and Razin (2007) show that globalization induces the central bank to put a larger relative weight on inflation than on the output gap in its welfare-based loss function, if compared with the case of a closed economy. Although I do not consider optimal monetary policy in the paper, I will test the hypothesis that monetary policy is influenced by globalization by letting the Taylor rule coefficients vary as a function of openness in one of the estimated specifications. This should capture, in reduced form, the possible channel of globalization on policy weights.

The variances of the disturbances hitting the economy may have also changed as a result of the increased integration of national economies. For example, an increase in international competition may have reduced the volatility of the mark-up shocks that appear in the inflation equation. The impact of globalization on the volatility of the shocks will also be investigated in the empirical section. 
The empirical results reveal only modest changes in the dynamics of macroeconomic variables that can be attributed to globalization. The slope of the Phillips curve has only marginally declined, despite a percentage of openness that has increased by a factor of four over the sample. The coefficient denoting the elasticity of domestic inflation to global output has indeed increased over the sample, but it remains very close to zero. Therefore, global slack is unlikely to play a relevant role in driving the U.S. inflation rate. The changes that globalization induces in the IS curve are also modest: the sensitivity of domestic output to real interest rates and foreign output terms have increased, but again not enough to significantly affect the dynamics of the economy. Global variables also do not substantially affect the formation of expectations, which remain mostly responsive to domestic developments. There is no evidence that globalization has made monetary policy less effective: the impulse responses show that policy shocks would have roughly the same effects if the U.S. economy was as open as in 2007 or if it was brought back to the levels of openness that existed in 1960.

Closed-economy specifications are always found to fit the data significantly better than the alternatives that incorporate information on the changing degrees of openness. This suggests that accounting for changes in globalization over time is not crucial in explaining post-1960 U.S. macroeconomic dynamics. As found by other authors (e.g., Sims and Zha, 2006), accounting for changes in the volatilities of the shocks is, instead, the feature that mostly helps in explaining the data. But assuming a single structural break in the early 1980s is still superior to allowing the volatilities to vary continuously as a function of openness (which would imply, instead, that the larger drop in volatility should start around 1990).

The estimates do not suggest that the economy has been stable over the whole period. They suggest, however, that globalization is unlikely to be the main driver of the changes. While largely different levels of openness fail to induce significant variation in the impulse responses to shocks, the estimated changes in the stance of expectations and in the state of agents' learning process can, instead, imply substantially different impulse responses at different points in the sample. 


\section{Model}

I study the effects of globalization on the U.S. economy using the following framework, based on the two-country open economy model first derived by Clarida, Galí, and Gertler, (2002): ${ }^{3}$

$$
\begin{aligned}
\pi_{t} & =\beta \hat{E}_{t} \pi_{t+1}+\kappa\left(\gamma_{t}\right) y_{t}+\kappa^{*}\left(\gamma_{t}\right) y_{t}^{*}+u_{t} \\
y_{t} & =\hat{E}_{t} y_{t+1}+\vartheta\left(\gamma_{t}\right)\left(\hat{E}_{t} y_{t+1}^{*}-y_{t}^{*}\right)-\tilde{\sigma}\left(\gamma_{t}\right)\left(i_{t}-\hat{E}_{t} \pi_{t+1}\right)+\eta_{t} \\
i_{t} & =\rho i_{t-1}+(1-\rho)\left[\chi_{\pi}\left(\gamma_{t}\right) \pi_{t-1}+\chi_{y}\left(\gamma_{t}\right) y_{t-1}\right]+\varepsilon_{t} .
\end{aligned}
$$

Equation (2.1) is an open-economy version of the New Keynesian Phillips curve: the domestic inflation rate, denoted by $\pi_{t}$, depends on future expected inflation (with a coefficient given by $\beta$, which represents the household's discount factor), on current domestic and foreign (or global) measures of output $y_{t}$ and $y_{t}^{*}$, and on a cost-push shock $u_{t}$ (which can arise endogenously in the model by assuming a time-varying elasticity of substitution among the goods produced by monopolistically-competitive firms). The coefficients $\kappa$ and $\kappa^{*}$ denote the sensitivity of inflation to the domestic and foreign output terms. Equation (2.2) is a log-linearized Euler equation derived from consumers' optimization, and it expresses current domestic output as a function of its one-period-ahead expectation, of the expected growth in foreign output, and of the ex-ante real interest rate; $\eta_{t}$ is a disturbance that acts as a preference shifter. Foreign output appears in the Euler equation from the assumption that domestic households consume a basket of both domestically and foreign-produced goods, i.e. $C_{t} \equiv C_{H, t}^{1-\gamma_{t}} C_{F, t}^{\gamma_{t}}$, where $\gamma_{t}$ denotes the share of foreign-produced goods in the consumption basket at each period $t$. The elasticities of domestic output to the foreign output terms and to the ex-ante real interest rate are denoted by $\vartheta$ and $\tilde{\sigma}$. Equation (2.3) describes monetary policy in the economy in the form of a Taylor rule with partial adjustment: the central bank gradually adjusts its policy instrument, a short-term nominal interest rate, denoted by $i_{t}$, in response to movements in lagged output and inflation (the rule is therefore operational in the sense of McCallum, 1999); the coefficient $\rho$ captures the inertia of interest rate decisions, while $\chi_{\pi}$ and $\chi_{y}$ denote the policy feedback coefficients. The $u_{t}$ and $\eta_{t}$ disturbances evolve as $\operatorname{AR}(1)$ processes as $u_{t}=\rho_{u} u_{t-1}+\sigma_{u}\left(\gamma_{t}\right) \nu_{t}^{u}$ and $\eta_{t}=\rho_{\eta} \eta_{t-1}+\sigma_{\eta}\left(\gamma_{t}\right) \nu_{t}^{\eta}$, while the monetary policy shock $\varepsilon_{t}$ is i.i.d.Normal with mean 0 and standard deviation $\sigma_{\varepsilon}$. A similar framework has been used elsewhere to investigate the potential effects of globalization: by Woodford (2007), to study the effects of globalization on

\footnotetext{
${ }^{3} \mathrm{~A}$ detailed derivation of the model can be found in Clarida, Galí, and Gertler, (2002), or Woodford (2007).
} 
the effectiveness of national monetary policies, by Zaniboni (2008), to evaluate the effects of openness on the Phillips curve in a calibrated model, and by Milani (2009a,b,c), to infer the role of global slack in domestic Phillips curves in the U.S. and G-7 countries. ${ }^{4}$

Several of the coefficients in eqs. (2.1) to (2.3) are allowed to depend on changes in globalization. Globalization is here modeled as the degree of openness to trade and it is measured by the parameter $\gamma_{t}$, which is allowed to vary over time. The reduced-form coefficients in the model are, in fact, a function of the openness coefficient $\gamma_{t}$ :

$$
\begin{aligned}
\kappa\left(\gamma_{t}\right) & =\xi\left[\omega+\sigma^{-1}+\gamma_{t}\left(1-\sigma^{-1}\right)\right] \\
\kappa^{*}\left(\gamma_{t}\right) & =-\xi \gamma_{t}\left(1-\sigma^{-1}\right) \\
\vartheta\left(\gamma_{t}\right) & =\gamma_{t}(1-\sigma) \\
\tilde{\sigma}\left(\gamma_{t}\right) & =\frac{\sigma}{\left(1-\vartheta\left(\gamma_{t}\right)\right)}
\end{aligned}
$$

as well as of the other 'deep' parameters $\xi \equiv \frac{(1-\alpha)(1-\alpha \beta)}{\alpha[1+(\phi-1) \epsilon]}>0, \omega \equiv[(1+\nu) \phi-1] \geq 0$, and $\sigma>0$, where $\sigma$ denotes the intertemporal elasticity of substitution, $\alpha$ denotes the Calvo price stickiness coefficient (the probability that a firm cannot reset its price in a given period), $0 \leq \phi^{-1} \leq 1$ is the labor share in the Cobb-Douglas production function, $\nu \geq 0$ is the inverse of the Frisch elasticity of substitution of labor supply, and $\epsilon>1$ is the elasticity of substitution among differentiated goods. The paper will exploit information about the evolution of $\gamma_{t}$ in the estimation: $\gamma_{t}$ will be set to correspond to the ratio of real imports of goods and services (seasonally-adjusted) to GDP at each point in the sample. The evolution of $\gamma_{t}$ over time is illustrated in Figure 1: $\gamma_{t}$ increases from around $4 \%$ in 1960 to above $17 \%$ by the end of the sample, and the pace of the increase is particularly pronounced starting from $1990 .^{5}$

Those reduced-form coefficients will therefore become time-varying, as a consequence of their dependence on the changing degree of openness. The model can hence capture the potential effects of globalization on the structure of the economy: globalization can change the slopes of the Phillips and IS curves, and it can make domestic variables a function of global output. The

\footnotetext{
${ }^{4}$ Milani (2009a,b,c) mainly focuses on estimating the reduced-form effect of global slack in domestic Phillips curve equations (that is, $\kappa^{*}$ in the current model) for the U.S. and G-7 countries, under different assumptions about expectations. This paper, instead, aims to assess the implications of globalization on the dynamics of U.S. variables by allowing several reduced-form coefficients to vary over time as a function of the globalization coefficient $\gamma_{t}$ (this paper directly estimates the structural coefficients and it also imposes the cross-equation restrictions in (2.4)-(2.7), which were, instead, not exploited in the other papers).

${ }^{5}$ Zaniboni (2008) uses a similar definition of globalization by considering it as a one-time increase in $\gamma$ in a calibrated model.
} 
sign and magnitude of these effects over time is an empirical question that will be investigated in the estimation section.

Other coefficients, which are not a direct function of openness in the structural model, will also be allowed to be influenced by globalization. The monetary policy coefficients, for example, will be allowed to vary over time depending on the degree of openness, in one of the various estimated specifications. The response coefficient to inflation and output will be given by

$$
\begin{aligned}
& \chi_{\pi}\left(\gamma_{t}\right)=\bar{\chi}_{\pi}+\lambda_{\chi_{\pi}} \gamma_{t} \\
& \chi_{y}\left(\gamma_{t}\right)=\bar{\chi}_{y}+\lambda_{\chi_{y}} \gamma_{t} .
\end{aligned}
$$

The dependence on the openness parameter in this case is not structural, but it is meant to indirectly capture the influence of openness on the policy preference weights: Loungani and Razin (2005) and Binyamini and Razin (2007), for example, demonstrate that central banks in more open economies should place a larger weight on the stabilization of inflation than output.

One may also think that globalization may have influenced the volatility of structural disturbances. For example, as the cost-push shock $u_{t}$ can be derived as a time-varying mark-up shock, it may be reasonable to assume that globalization has led to increased competition and, hence, dampened the volatility of this inflationary shock. This possibility will again be tested in a flexible way by allowing, in one of the alternative specifications, the standard deviations to vary with openness as

$$
\begin{aligned}
& \sigma_{u}\left(\gamma_{t}\right)=\bar{\sigma}_{u}+\lambda_{\sigma_{u}} \gamma_{t} \\
& \sigma_{\eta}\left(\gamma_{t}\right)=\bar{\sigma}_{\eta}+\lambda_{\sigma_{\eta}} \gamma_{t} .
\end{aligned}
$$

Finally, we need to specify a law of motion for foreign output. The foreign economy is not modeled as structural, but, nevertheless, it is allowed to be influenced by U.S. economic conditions. Global output, in fact, is expressed by the following equation

$$
y_{t}^{*}=\rho_{y *} y_{t-1}^{*}+\delta_{y} y_{t-1}-\delta_{r}\left(i_{t-1}-\pi_{t-1}\right)+\nu_{t},
$$

which permits to control for the influence of past U.S. output and real interest rates on global output. The shock to global output $\nu_{t}$ follows an AR(1) process with autoregressive coefficient $\rho_{\nu}$ and standard deviation $\sigma_{\nu}{ }^{6}$

\footnotetext{
${ }^{6}$ A structural model for the foreign economy may not be realistic, since it would need to summarize the dynamics of a large group of several heterogeneous countries. I therefore choose to work with a more empiricallyoriented backward-looking specification.
} 
The conventional closed-economy New Keynesian model is nested as the special case in which $\gamma_{t}=0$ at all $t$ 's. Different closed-economy specifications will also be estimated and compared with the baseline open economy model.

2.1. Expectations Formation and Learning. The assumption of rational expectations is relaxed: agents are assumed to form near-rational expectations and they are allowed to learn over time (see Evans and Honkapohja, 2001, for a comprehensive treatment of similar models of expectations formation). Agents estimate the following specification, which represents their perceived law of motion (PLM) of the economy

$$
Y_{t}=a_{t}+b_{t} Y_{t-1}+e_{t}
$$

where

$$
a_{t}=\left[\begin{array}{c}
a_{t}^{\pi} \\
a_{t}^{y} \\
a_{t}^{i} \\
a_{t}^{y^{*}}
\end{array}\right], b_{t}=\left[\begin{array}{cccc}
b_{t}^{\pi, \pi} & b_{t}^{\pi, y} & b_{t}^{\pi, i} & b_{t}^{\pi, y^{*}} \\
b_{t}^{y, \pi} & b_{t}^{y, y} & b_{t}^{y, i} & b_{t}^{y, y^{*}} \\
b_{t}^{i, \pi} & b_{t}^{i, y} & b_{t}^{i, i} & b_{t}^{i, y^{*}} \\
b_{t}^{y^{*}, \pi} & b_{t}^{y^{*}, y} & b_{t}^{y^{*}, i} & b_{t}^{y^{*}, y^{*}}
\end{array}\right]
$$

and $Y_{t} \equiv\left[\pi_{t}, y_{t}, i_{t}, y_{t}^{*}\right]^{\prime} ; e_{t}$ is a vector of residuals. The PLM has the same structural form as the minimum state variable solution of the system under rational expectations, but agents are assumed not to observe the structural disturbances and they lack knowledge about the parameters of the economy. Therefore, agents use the available historical data to infer the reduced-form coefficients in $a_{t}$ and $b_{t}$ (although the true constants in the rational expectations solution will be equal to zero, agents are not endowed with this information and, therefore, they also learn about the intercepts $a_{t}$ ). They update their coefficient estimates over time according to the constant-gain algorithm

$$
\begin{aligned}
\widehat{\phi}_{t} & =\widehat{\phi}_{t-1}+\overline{\mathbf{g}} R_{t}^{-1} X_{t}\left(Y_{t}-X_{t}^{\prime} \widehat{\phi}_{t-1}\right) \\
R_{t} & =R_{t-1}+\overline{\mathbf{g}}\left(X_{t} X_{t}^{\prime}-R_{t-1}\right)
\end{aligned}
$$

where $\widehat{\phi}_{t}=\left(\left[a_{t}^{\pi}, \ldots, a_{t}^{y^{*}}\right]^{\prime},\left[b_{t}^{\pi, \pi}, \ldots, b_{t}^{y^{*}}, y^{*}\right]^{\prime}\right)^{\prime}$ describes the updating of the learning rule coefficients, while $R_{t}$ describes the updating of the matrix of second moments of the stacked regressors $X_{t} \equiv\left\{1, Y_{t-1}\right\}$. The coefficient $\overline{\mathbf{g}}$ denotes the constant gain, which is the parameter that governs the rate at which agents discount past information when forming their beliefs. The constant gain will be jointly estimated along with the rest of the structural parameters in the empirical section. 
Economic agents use (2.13) and the updated parameter estimates in (2.14) and (2.15), to form their expectations for variables in $t+1$ as

$$
\widehat{E}_{t-1} Y_{t+1}=\left(I+b_{t}\right) a_{t}+b_{t}^{2} Y_{t-1}
$$

where it is assumed that agents dispose of information up to $t-1$ (as customary in the adaptive learning literature), when forming expectations in $t$, and which can be substituted in the model formed by equations (2.1), (2.2), (2.3), and (2.12), to obtain the Actual Law of Motion of the economy (ALM). The ALM can then be expressed in state-space form as:

$$
\begin{aligned}
\xi_{t} & =A_{t}\left(\gamma_{t}\right)+F_{t}\left(\gamma_{t}\right) \xi_{t-1}+G\left(\gamma_{t}\right) \varpi_{t} \\
Y_{t} & =H \xi_{t},
\end{aligned}
$$

where $\xi_{t}=\left[Y_{t}^{\prime}, u_{t}, \eta_{t}, \nu_{t}\right]^{\prime}$ is a vector of state variables, $Y_{t}$ is the vector of observable variables, $\varpi_{t}$ is a vector of Normally-distributed exogenous innovations, $A_{t}\left(\gamma_{t}\right)$ is a vector of intercept terms, $F_{t}\left(\gamma_{t}\right)$ is a matrix of coefficients that depends on structural and beliefs coefficients, $G\left(\gamma_{t}\right)$ collects the standard deviations of the innovations, and $H$ is a $4 \times 7$ matrix of zeros and ones, which simply selects the observables from the vector of state variables $\xi_{t}$. In the empirical section, I will estimate the state-space model in (2.17)-(2.18); $A_{t}\left(\gamma_{t}\right), F_{t}\left(\gamma_{t}\right)$, and $G\left(\gamma_{t}\right)$ will be allowed to change as a function of the degree of openness in the economy and they will be hence time-varying (agents' real-time learning also contributes to make the ALM time-varying). ${ }^{7}$

Through the assumption of near-rational expectations and learning, the paper tries to assess the role of globalization on the formation of expectations and whether its perceived effects have changed over time. The empirical section will consider, in fact, different specifications in which the PLM includes or not global output terms (the baseline specification, for example, assumes that $b_{t}^{\pi, y^{*}}=b_{t}^{y, y^{*}}=b_{t}^{i, y^{*}}=0$ in (2.13), but I will also estimate an alternative specification in which the coefficients are left unconstrained and hence global output can potentially affect expectations about domestic variables) or in which the perceived steady-state level of inflation may be related to openness. In this latter case, the intercept term in the inflation equation in

\footnotetext{
${ }^{7}$ I do not estimate a single specification in which all coefficients are allowed to vary with the extent of globalization. Instead, I will estimate, in turn, a specification in which only the coefficients in (2.4)-(2.7) depend on openness, one in which, besides the coefficients in (2.4)-(2.7), only the monetary policy coefficients (or the standard deviations of the shocks) depend on openness, and so forth.
} 
the PLM becomes a function of openness as

$$
a_{t}^{\pi}\left(\gamma_{t}\right)=a_{t}^{\pi}+\lambda_{a_{t}^{\pi}} \gamma_{t}
$$

Learning can be also seen as a mechanism to capture persistence in the model: in this way, it replaces alternative assumptions that have been used in the literature, such as the need to modify the utility function to include habit formation in consumption or to assume automatic indexation of monopolistic firms' prices to the past aggregate inflation rate (e.g., Milani, 2007).

\section{ECONOMETRIC Approach}

3.1. Data. I use quarterly data on U.S. domestic inflation, U.S. output, the Federal Funds rate, and 'global' output, as observable variables in the estimation. The sample spans the period from 1960:q1 to 2007:q1, which is characterized by a large increase in the openness of the U.S. economy.

Inflation is calculated as the log quarterly change in the GDP Implicit Price Deflator, output is obtained as log Real GDP, which is detrended using the Hodrick-Prescott filter, and the Federal Funds rate is used as the monetary policy instrument (the data are derived from FRED ${ }^{\circledR}$, the database maintained by the Federal Reserve Bank of St. Louis). To obtain the relevant measure of global output for the U.S. economy, I select the largest 50 U.S. trading partners in 2007 and use quarterly data (all seasonally-adjusted) on their real GDP, and their bilateral exports and imports with the U.S. over the sample (the data for the trading partners have been obtained from IHS Global Insight). ${ }^{8}$ A detrended output series is derived for each country using the HP filter. Global output $y_{t}^{*}$ is then obtained as a weighted average of the countries' detrended output series in period $t$ :

$$
\begin{aligned}
y_{t}^{*} & =\sum_{i=1}^{N} w_{t}^{i} y_{t}^{i} \\
w_{t}^{i} & =\frac{\left(\text { Import }_{t}^{i}+\text { Export }_{t}^{i}\right)}{\sum_{i=1}^{N}\left(\text { Imports }_{t}^{i}+\text { Exports }_{t}^{i}\right)},
\end{aligned}
$$

\footnotetext{
${ }^{8}$ Only annual GDP series are available for some of the countries, which are therefore dropped from the analysis. Since these countries occupy positions between 35 and 50 in the trading partners' rankings, their omission is unlikely to have any sizeable effect on the results. Global output is, at the end, calculated using data on about 40 countries: Argentina, Australia, Austria, Belgium, Brazil, Canada, Chile, China, Colombia, Costa Rica, Denmark, Ecuador, Finland, France, Germany, Hong Kong, India, Indonesia, Ireland, Israel, Italy, Japan, South Korea, Malaysia, Mexico, Netherland, Norway, New Zealand, Philippines, Russia, South Africa, Singapore, Spain, Sweden, Switzerland, Thailand, Turkey, U.K., and Venezuela.
} 
where $i=1, \ldots, N$ is an index for the different trading partners, $y_{t}^{i}$ is the detrended output of trading partner $i$, and where the weights $w_{t}^{i}$ are given by the sum of U.S. imports and exports with country $i$ in each period $t$ as a fraction of total U.S. imports and exports with the set of trading partners.

The evolution of the U.S. and global output series is shown in Figure 2. Global output measures obtained along the same lines have been used in Borio and Filardo (2007) and Ihrig et al. (2007) (the same global slack series for the U.S. has been used in Milani, 2009a,b,c). The large set of trading partners permits to account for the influence of emerging market economies, particularly in the recent part of the sample in which they are likely to be more important. Moreover, the construction of global output using trade weights is motivated by the observation that bilateral trade flows seem to remain the main source of global linkages (e.g., Forbes and Chinn, 2004, and Frankel and Rose, 1998).

3.2. Parameters and Prior Distributions. In the baseline specification, I will estimate the following set of structural parameters, which are collected in the vector $\Theta$ :

$$
\Theta=\left\{\alpha, \sigma, \rho, \chi_{\pi}, \chi_{y}, \rho_{u}, \rho_{\eta}, \rho_{\nu}, \sigma_{u}, \sigma_{\eta}, \sigma_{\varepsilon}, \sigma_{\nu}, \delta_{y}, \delta_{r}, \rho_{y^{*}}, \overline{\mathbf{g}}\right\}
$$

Some of the reduced-form parameters in the model, $\kappa\left(\gamma_{t}\right), \kappa^{*}\left(\gamma_{t}\right), \vartheta\left(\gamma_{t}\right)$, and $\tilde{\sigma}\left(\gamma_{t}\right)$, are a function of $\gamma_{t}$ and, therefore, they will vary continuously over time depending on the degree of openness in the economy. The openness coefficient $\gamma_{t}$ will be fixed in the estimation to the values shown in Figure 1. In other specifications, I will also allow different subsets of the parameters in $\Theta$ - including either the monetary policy coefficients $\chi_{\pi}\left(\gamma_{t}\right)$ and $\chi_{y}\left(\gamma_{t}\right)$, coefficients describing agents' expectations, or the standard deviations of the shocks $\sigma_{u}\left(\gamma_{t}\right)$ and $\sigma_{\eta}\left(\gamma_{t}\right)$ - to be influenced in a flexible way by the varying degree of openness.

Table 1 specifies the prior distributions for the parameters in $\Theta$. I select a Beta distribution with mean 0.7 and standard deviation 0.08 for the Calvo coefficient $\alpha$ and a Gamma distribution with mean 1 and standard deviation 0.75 for the intertemporal elasticity of substitution $\sigma$. The policy rule feedback coefficients to inflation and output follow Normal distributions with mean 1.5 and 0.5. I choose a Beta prior for all the autoregressive coefficients, and inverse Gamma for the standard deviations of the shocks. I also assume a Beta prior distribution for the constant gain coefficient, which places most probability mass on values in the interval between 0 and 0.15 (larger values would imply unrealistically high degrees of volatility in the economy). 
Some coefficients have been fixed: the discount factor $\beta$ is fixed at $0.99, \phi$ is assumed equal to $3, \nu$ is set equal to $1 / 9.5$ as in Rotemberg and Woodford (1998), and $\epsilon$ is fixed at 7 (which implies a mark-up of prices over marginal costs of $16 . \overline{6} \%$ ). The learning process in (2.14)(2.15) needs to be initialized. The initial beliefs of the agents at the beginning of the sample in 1960 are informed by pre-sample data. These indicate a limited degree of persistence in inflation $\left.b_{t}^{\pi, \pi}=0.6\right)$, high autoregressive coefficients in the output and interest rate equations $\left(b_{t}^{y, y}=b_{t}^{i, i}=0.8\right)$, and relatively high sensitivities of inflation to output $\left(b_{t}^{\pi, y}=0.1\right)$ and of output to real interest rates $\left(b_{t}^{y, \pi}=-b_{t}^{y, i}=1\right)$. The precision matrix $R_{t}$ is initialized at

the beginning of the sample using 1947-1959 data, as $R_{t=0}=\left[\overline{\mathbf{g}} \sum_{i=1}^{\tau}(1-\overline{\mathbf{g}})^{(i-1)} X_{\tau-i}^{\prime} X_{\tau-i}\right]$, where $i=1, \ldots, \tau$ indicates the pre-sample observations. While different initial values may imply some differences in the evolution of beliefs over the sample, all the conclusions regarding the effects of globalization are unaffected.

The model is estimated using a full-information Bayesian approach. Draws from the posterior distribution are obtained using the Metropolis-Hastings algorithm. I run 500,000 draws for each estimated specification, discarding the first $25 \%$ as initial burn-in.

\section{EMPiRical Results}

The posterior estimates for the structural parameters are shown in Table 2; column (1) reports the results for the baseline specification. The posterior mean for the Calvo price stickiness coefficient $\alpha$ equals 0.852 , while $\sigma$ has a posterior mean of 0.141 . The estimates for the monetary policy feedback coefficients equal 1.204 for $\chi_{\pi}$ and 0.376 for $\chi_{y}$; the estimated reaction to inflation is on the low side of typical estimates as it refers to the whole post-1960 sample (I will later estimate specifications, however, in which the policy coefficients are allowed to change over time). The posterior mean for the constant gain coefficient is equal to 0.034 , which is in the range of values considered reasonable in the adaptive learning literature. It should be noticed that learning appears successful in inducing inertia in the system, since the remaining serial correlation that is picked up by the exogenous disturbances is limited $\left(\rho_{u}=0.198\right.$ and $\left.\rho_{\eta}=0.349\right)$.

The slope of the Phillips curve and the sensitivity of inflation to the global output measure, denoted by $\kappa$ and $\kappa^{*}$, are functions of the estimated structural parameters and can vary over time, as they also depend on the openness index $\gamma_{t}$, which is time-varying. In the IS equation, 
the sensitivity of domestic output to the real interest rate and to the expected growth of global output, denoted by $\vartheta$ and $\tilde{\sigma}$, are also affected by the openness of the economy.

The evolution of these estimated coefficients over the sample is shown in Figure 2 (which displays the mean across draws, along with $17 \%$ and $83 \%$ percentiles). The change in the slope of the Phillips curve induced by the increased openness of the U.S. economy is negligible: $\kappa$ changes only from 0.0127 to 0.0115 . The graph shows that the sensitivity of inflation to global output has increased over time, but the role of global output remains small. The value of $\kappa^{*}$ remains equal to only 0.0015 at the end of the sample. Overall, it doesn't appear that globalization has radically transformed the structure of the Phillips curve. The sensitivity of U.S. output to global output and domestic interest rates has increased over the sample, although the effects are again far from dramatic.

Globalization may have also affected the formation of private sector's expectations. Economic agents may include information about global output in their PLM and learn about its effect on the domestic economy (in this case, in the estimation the PLM is now equal to (2.13) and no longer imposes $b_{t}^{\pi, y^{*}}=b_{t}^{y, y^{*}}=b_{t}^{i, y^{*}}=0$ as in the baseline specification). The corresponding posterior estimates for this case are reported under column (2) in the table. Moreover, globalization may affect the formation of inflation expectations in another way, by leading agents to expect a permanently lower level of steady-state inflation (the estimates for this case are shown in column (4)): to test this possibility, the intercept in the agents' PLM for inflation is allowed to depend on $\gamma_{t}$ as described in (2.19). The coefficient $\lambda_{a_{t}^{\pi}}$ will also be estimated, assuming a Uniform prior over a wide support (U[-20,20]).

The results indicate that globalization is unlikely to have altered the formation of expectations. The last rows of Table 2 show the models' marginal likelihoods (calculated using Geweke's modified harmonic mean approximation) and the Bayes factors among the different specifications (which are all computed with respect to the baseline open economy model). The marginal likelihoods indicate that the data favor the specification in which global output is ignored in the PLM to forecast domestic variables: the Bayes factor with respect to the baseline model is 0.06 (according to Jeffrey's (1961) interpretative scale, Bayes factors above 10 or below 0.1 provide 'strong' evidence in favor of one model versus the other). The perceived 
steady-state level of inflation also does not appear to be influenced by the increased globalization $\left(\lambda_{a_{t}^{\pi}}\right.$ is equal to only -0.048, which implies an evolution of perceived steady-state inflation largely similar to that in the baseline case, and the Bayes factor is only 0.014).

In columns (3) and (5), I test whether the monetary policy feedback coefficients and the standard deviations of the disturbances have been affected by globalization. In this case, the dependence on globalization is not entirely structural, since the policy coefficients and the volatilities are not a direct function of $\gamma_{t}$ in the model. I use, however, the empirical specifications described in (2.8)-(2.9) and (2.10)-(2.11) to verify whether the policy coefficients $\chi_{\pi}$ and $\chi_{y}$ and the standard deviations $\sigma_{u}$ and $\sigma_{\eta}$ have varied with openness. The constant parts of the coefficients, i.e. $\bar{\chi}_{\pi}, \bar{\chi}_{y}, \bar{\sigma}_{u}$, and $\bar{\sigma}_{\eta}$, follow the same priors as the corresponding coefficients $\chi_{\pi}, \chi_{y}, \sigma_{u}$, and $\sigma_{\eta}$. I select, instead, Uniform priors for $\lambda_{\sigma_{u}}$ and for $\lambda_{\sigma_{\eta}}$ (both with support $[-5,5])$ and $\Gamma(1.5,1 / 4)$ priors for $\lambda_{\chi_{\pi}}$ and $-\lambda_{\chi_{y}}$, which imply a mean equal to 6 and standard deviation equal to 4.9; the latter priors, by restricting the sign of the coefficients, impose the knowledge that monetary policy has become more aggressive toward inflation and less toward output over time. The posterior means fall far enough from the prior means, suggesting that the data are informative.

Figure 4 illustrates the estimated evolution of the coefficients over the sample. ${ }^{9}$ The estimates suggest a slightly more aggressive reaction of monetary policy to inflation (the sign of the effect is assumed through the prior, while its size is inferred from the data) and a slightly less aggressive reaction to output over time $\left(\chi_{\pi}\right.$ changes from 1.24 to $1.56, \chi_{y}$ goes from 0.37 to $0.23)$, and they indicate a large reduction in the volatilities of the supply and demand shocks, with a decline from 0.35 to 0.23 for $\sigma_{u}$ and from 0.99 to 0.42 for $\sigma_{\eta}$. In the next section, I will, however, compare the fit of these specifications with the fit of alternative specifications in which the time variation is unrelated to changes in openness.

\subsection{Are Closed-Economy Models of the U.S. Economy Obsolete? How important} are changes in globalization in explaining the evolution of U.S. macroeconomic variables in the post-war period? In this section, I re-estimate the model for the U.S. economy under the more commonly used hypothesis of a closed economy (this is simply done by fixing the openness parameter $\gamma_{t}$ to 0 for all $t$ 's). The fit of the various closed and open economy specifications

\footnotetext{
${ }^{9}$ The evolution of $\kappa, \kappa^{*}, \vartheta$, and $\tilde{\sigma}$, is not shown as it is similar to the previous case.
} 
can again be compared by considering the models' marginal likelihoods. The closed economy version fits the data better than the open economy specification that allows for a time-varying degree of openness. The Bayes factor is slightly above 10 .

In the previous section, I have tested whether the policy coefficients and the volatilities may be time-varying as a result of changes in openness. But they may vary over time also for different reasons, which may be unrelated to globalization. I re-estimate the closed economy model, now allowing, in turn, either the policy coefficients to switch at one point in the sample (in 1979, in correspondence of Volcker's appointment as Fed's Chairman) or the standard deviations (in 1984, which is generally regarded as the starting date for the "Great Moderation"). Finally, I estimate a specification in which the slope of the Phillips curve is allowed to assume different values in the pre- and post-1984 samples. The priors will assume the same mean for the coefficients before and after the switch. These alternatives allow me to compare the fit to the data between closed economy models with a single structural break in some of the coefficients around the early 1980s and their open-economy counterparts in which the same coefficients vary, instead, continuously as a function of changes in globalization. The posterior estimates point to changes in the policy coefficients, with the reaction to inflation increasing from 1.02 to 1.491 and the reaction to output declining from 0.381 to 0.28 , and in the degree of price stickiness $\alpha$, which rises from 0.841 to 0.903 and which implies a reduction in the slope of the Phillips curve $\kappa$ from 0.015 to 0.0078 (hence considerably larger than the small change implied by globalization). In particular, there is strong evidence of a fall in the volatilities of the shocks: the standard deviations $\sigma_{u}$ and $\sigma_{\eta}$ fall from 0.361 to 0.26 and from 1.086 to 0.5.

The closed-economy models all attain marginal likelihood values that are above those of the corresponding open economy specifications. While the evidence on time variation in the monetary policy rule coefficients or in the slope of the Phillips curve is inconclusive (the marginal likelihoods are very close to each other), the data clearly favor any specification that allows the volatilities of the shocks to vary over time. In this case, however, a single switch in the early 1980s is preferred to the continuously-changing volatilities influenced by openness.

4.2. Globalization and the Effects of Monetary Policy Shocks. It has been argued that globalization may have substantially reduced the effectiveness of national monetary policies. 
I compute the impulse responses of output and inflation to a monetary policy shock under different degrees of openness of the U.S. economy. Figure 5 shows the response to a onestandard-deviation monetary policy shock that takes place at the end of the sample (in 2007:I), hence, with a degree of openness equal to 0.174 ; the response is then compared with responses in the same conditions, but assuming that the U.S. economy is just as open as in the early part of the sample (as in 1960:I), or that it is entirely closed to international trade. Globalization has not reduced the power of monetary policy. The response of macro variables to a policy shock is slightly larger in the more open case than in the alternatives (the effect is slightly larger because globalization raises the sensitivity of output to changes in the interest rate $\tilde{\sigma}$ from 0.145 to 0.165 ), but the responses are generally very close to each other.

Therefore, changes in the openness of the U.S. economy of the size that have been observed so far, from $4 \%$ to $17 \%$, are unlikely to have significantly altered the transmission mechanism of monetary policy.

Yet, the empirical results do not suggest that the response to shocks has been constant over the whole post-1960 sample. Simply, globalization is unlikely to have been the main culprit. Figure 6, for example, compares the responses of output and inflation to a monetary policy shock in 1982 with those in 2007. The responses were much stronger in 1982 than at the end of the sample. But a different stance of expectations and learning (possibly related to a different stance in monetary policy and an enhanced degree of central bank's credibility), rather than the increase in globalization, are responsible for the evolving response of the economy to shocks.

\section{Concluding Remarks and Future Directions}

The paper has presented an estimated model in which several of the key relationship in the economy are potentially affected by the degree of globalization.

Globalization doesn't seem to have substantially altered the behavior of macroeconomic variables as output and inflation. The increased globalization can account for only a modest decrease in the slope of the Phillips curve; the role of global output in the Phillips curve has somewhat increased over time, but even at the end of the sample it remains minor. The changes induced by globalization on the IS equation are similarly moderate. A closed economy specification still fits the evolution of U.S. time series data better than open economy specifications in which the degree of openness is allowed to vary over time. 
This paper is admittedly a first step in the study of the structural effects of globalization. There are several elements of globalization that are missing from the model. The paper considers openness to trade, but it does not focus on global financial integration and it abstract from any channel from financial markets to the economy (some implications of international financial integration are investigated in Milani, 2008). Other papers have emphasized the potential role of global variables other than global slack, such as global liquidity (e.g., D'Agostino and Surico, 2009). Globalization may reinforce the competitive pressures that domestic firms face and hence reduce their pricing power (Sbordone, 2007, studies the impact of the entry of new firms, which is possibly induced by globalization, on the slope of the Phillips curve). Future research may incorporate these additional channels in a general equilibrium model and analyze whether they play an empirically relevant role.

In the sample, the degree of openness rose from $4 \%$ to $17 \%$ : such an increase is unable to justify large changes in the dynamics of the economy. But it cannot be excluded that further increases in openness may in the future induce deeper transformations in the U.S. economy than those that have occurred so far.

\section{REFERENCES}

[1] Ball, L., (2006). "Has Globalization Changed Inflation?", NBER Working Paper 12687.

[2] Bank for International Settlements, (2006), 76th Annual Report 2005/2006, Basel, Switzerland.

[3] Binyamini, A., and A. Razin, (2007). "Flattened Inflation-Output Tradeoff and Enhanced Anti-Inflation Policy: Outcome of Globalization?" NBER Working Paper 13280.

[4] Boivin, J., and M. Giannoni, (2007). "Global Forces and Monetary Policy Effectiveness", in J. Gali and M. J. Gertler ed., International Dimensions of Monetary Policy, University of Chicago Press.

[5] Borio, C., and A. Filardo, (2007). "Globalisation and Inflation: New Cross-Country Evidence on the Global Determinants of Domestic Inflation," Working Paper No 227, Bank for International Settlements.

[6] Castelnuovo, E., (2007). "Tracking U.S. Inflation Expectations with Domestic and Global Determinants," mimeo, University of Padua.

[7] Clarida, R., J. Galí, and M. Gertler, (2002). "A Simple Framework for International Monetary Policy Analysis", Journal of Monetary Economics, 49, 879-904.

[8] D'Agostino, A., and P. Surico, (2009). "Does Global Liquidity Help to Forecast US Inflation?", Journal of Money, Credit and Banking, Vol. 41, 479-489.

[9] Evans, G. W., and S. Honkapohja (2001). Learning and Expectations in Economics. Princeton, Princeton University Press.

[10] Feenstra, R.C., and G.H. Hanson, (1996). "Globalization, Outsourcing, and Wage Inequality," American Economic Review, vol. 86(2), pages 240-45.

[11] Fisher, R., (2005). "Globalization and Monetary Policy", Warren and Anita Manshel Lecture in American Foreign Policy, Harvard University, Cambridge, MA.

[12] Fisher, R., (2006). "Coping with Globalization's Impact on Monetary Policy", Remarks for the National Association for Business Economics Panel Discussion at the 2006 Allied Social Science Associations Meeting Boston, MA.

[13] Forbes, K. J., and M. D. Chinn, (2004). "A Decomposition of Global Linkages in Financial Markets Over Time," The Review of Economics and Statistics, vol. 86(3), pages 705-722. 
[14] Frankel, J.A., and A.K Rose, (1998). "The Endogeneity of the Optimum Currency Area Criteria", The Economic Journal, Vol. 108, No. 449, pp. 1009-1025.

[15] Gamber, E. N., and J. H. Hung, (2001), "Has the Rise in Globalization Reduced U.S. Inflation in the 1990s?", Economic Inquiry, Volume 39, Issue 1, Page 58-73.

[16] Ihrig, J., Kamin, S. B., Lindner, D., and J. Marquez, (2007). "Some Simple Tests of the Globalization and Inflation Hypothesis," Board of Governors of the Federal Reserve System, IF Discussion Paper No. 891.

[17] Jeffreys, H., (1961). Theory of Probability, Oxford University Press, Oxford.

[18] Loungani, P., and A. Razin, (2005). "Globalization and Inflation-Output Tradeoffs," NBER Working Paper 11641.

[19] McCallum, B. T., (1999). "Issues in the Design of Monetary Policy Rules", in J.B. Taylor and M. Woodford (ed.), Handbook of Macroeconomics, chap. 23, 1483-1530.

[20] Milani, F., (2007). "Expectations, Learning and Macroeconomic Persistence", Journal of Monetary Economics, Vol. 54, Iss. 7, pages 2065-2082.

[21] Milani, F., (2008). "The Impact of Foreign Stock Markets on Macroeconomic Dynamics in Open Economies: a Structural Estimation", mimeo, University of California, Irvine.

[22] Milani, F., (2009a). "Has Global Slack Become More Important than Domestic Slack in Determining U.S. Inflation?", Economics Letters, Volume 102, Issue 3, pages 147-151.

[23] Milani, F., (2009b). "Global Slack and Domestic Inflation Rates: A Structural Investigation for G-7 Countries", mimeo, University of California, Irvine.

[24] Milani, F., (2009c). "The Effect of Global Output on U.S. Inflation and Inflation Expectations: a Structural Estimation", mimeo, University of California, Irvine.

[25] Rogoff, K.S., (2003) "Globalization and Global Disinflation" in Monetary Policy and Uncertainty: Adapting to a Changing Economy, Federal Reserve Bank of Kansas City.

[26] Rogoff, K.S., (2007) "Impact of Globalization on Monetary Policy," in The New Economic Geography: Effects and Policy Implications, Federal Reserve Bank of Kansas City.

[27] Romer, D., (1993). "Openness and Inflation: Theory and Evidence", The Quarterly Journal of Economics, Vol. 108, No. 4, pp. 869-903.

[28] Rotemberg, J., and M. Woodford, (1998). "An Optimization-Based Econometric Framework for the Evaluation of Monetary Policy," NBER Macroeconomics Annual, The MIT Press, Cambridge, MA, pp. 297-346.

[29] Sbordone, A., (2007). "Globalization and Inflation Dynamics: The Impact of Increased Competition," in J. Gali and M. J. Gertler ed., International Dimensions of Monetary Policy, University of Chicago Press.

[30] Sims, C.A., and T. Zha, (2006). "Were There Regime Switches in U.S. Monetary Policy?," American Economic Review, vol. 96(1), pages 54-81.

[31] Tootell, G., (1998). "Globalization and U.S. Inflation", Federal Reserve Bank of Boston, New England Economic Review, pp. 21-33.

[32] Woodford, M. (2007) "Globalization and Monetary Control," in J. Gali and M. J. Gertler ed., International Dimensions of Monetary Policy, University of Chicago Press.

[33] Wynne, M.A., and E.K. Kersting (2007), "Openness and Inflation," Federal Reserve of Dallas Staff Paper No. 2.

[34] Zaniboni, N., (2008). "Globalization and the Phillips Curve", mimeo, Princeton University. 


\begin{tabular}{l|c|l|l|c|c}
\hline \hline & & \multicolumn{4}{|c}{ Prior Distribution } \\
\hline Description & Parameter & Distr. & Support & Prior Mean & $95 \%$ Prior Prob. Interval \\
\hline Price Stickiness & $\alpha$ & $B$ & {$[0,1]$} & 0.7 & {$[0.53,0.85]$} \\
Intertemp. El. Subst. & $\sigma$ & $\Gamma$ & $\mathbb{R}^{+}$ & 1 & {$[0.1,2.91]$} \\
MP Inertia & $\rho$ & $B$ & {$[0,1]$} & 0.8 & {$[0.46,0.99]$} \\
MP Inflation feedback & $\chi_{\pi}$ & $N$ & $\mathbb{R}$ & 1.5 & {$[1.01-1.99]$} \\
MP Output feedback & $\chi_{y}$ & $N$ & $\mathbb{R}$ & 0.25 & {$[0.01-0.49]$} \\
AR coeff. $u_{t}$ & $\rho_{u}$ & $B$ & {$[0,1]$} & 0.5 & {$[0.17-0.83]$} \\
AR coeff. $\eta_{t}$ & $\rho_{\eta}$ & $B$ & {$[0,1]$} & 0.5 & {$[0.17-0.83]$} \\
AR coeff. $\nu_{t}$ & $\rho_{\nu}$ & $B$ & {$[0,1]$} & 0.5 & {$[0.17-0.83]$} \\
Std. Cost-Push Shock & $\sigma_{u}$ & $\Gamma^{-1}$ & $\mathbb{R}^{+}$ & 0.5 & {$[0.1,1.92]$} \\
Std. Demand Shock & $\sigma_{\eta}$ & $\Gamma^{-1}$ & $\mathbb{R}^{+}$ & 0.5 & {$[0.1,1.92]$} \\
Std. MP Shock & $\sigma_{\varepsilon}$ & $\Gamma^{-1}$ & $\mathbb{R}^{+}$ & 0.5 & {$[0.1,1.92]$} \\
Std. Global Output Shock & $\sigma_{\nu}$ & $\Gamma^{-1}$ & $\mathbb{R}^{+}$ & 0.5 & {$[0.1,1.92]$} \\
Effect of US Output on $y_{t}^{*}$ & $\delta_{y}$ & $N$ & $\mathbb{R}^{*}$ & 0 & {$[-0.98,0.98]$} \\
Effect of US Real Rate on $y_{t}^{*}$ & $\delta_{r}$ & $\Gamma$ & $\mathbb{R}^{+}$ & 0.0625 & {$[0.01,0.17]$} \\
AR coeff. $y_{t}^{*}$ & $\rho_{y *}$ & $B$ & {$[0,1]$} & 0.7 & {$[0.47,0.89]$} \\
Constant Gain & $\mathbf{g}$ & $B$ & {$[0,1]$} & 0.05 & {$[0.003,0.151]$} \\
\hline \hline
\end{tabular}

Table 1 - Prior Distributions.

Note: $\Gamma=$ Gamma, $N=$ Normal, $B=$ Beta, $\Gamma^{-1}=$ Inverse Gamma, $U=$ Uniform, 


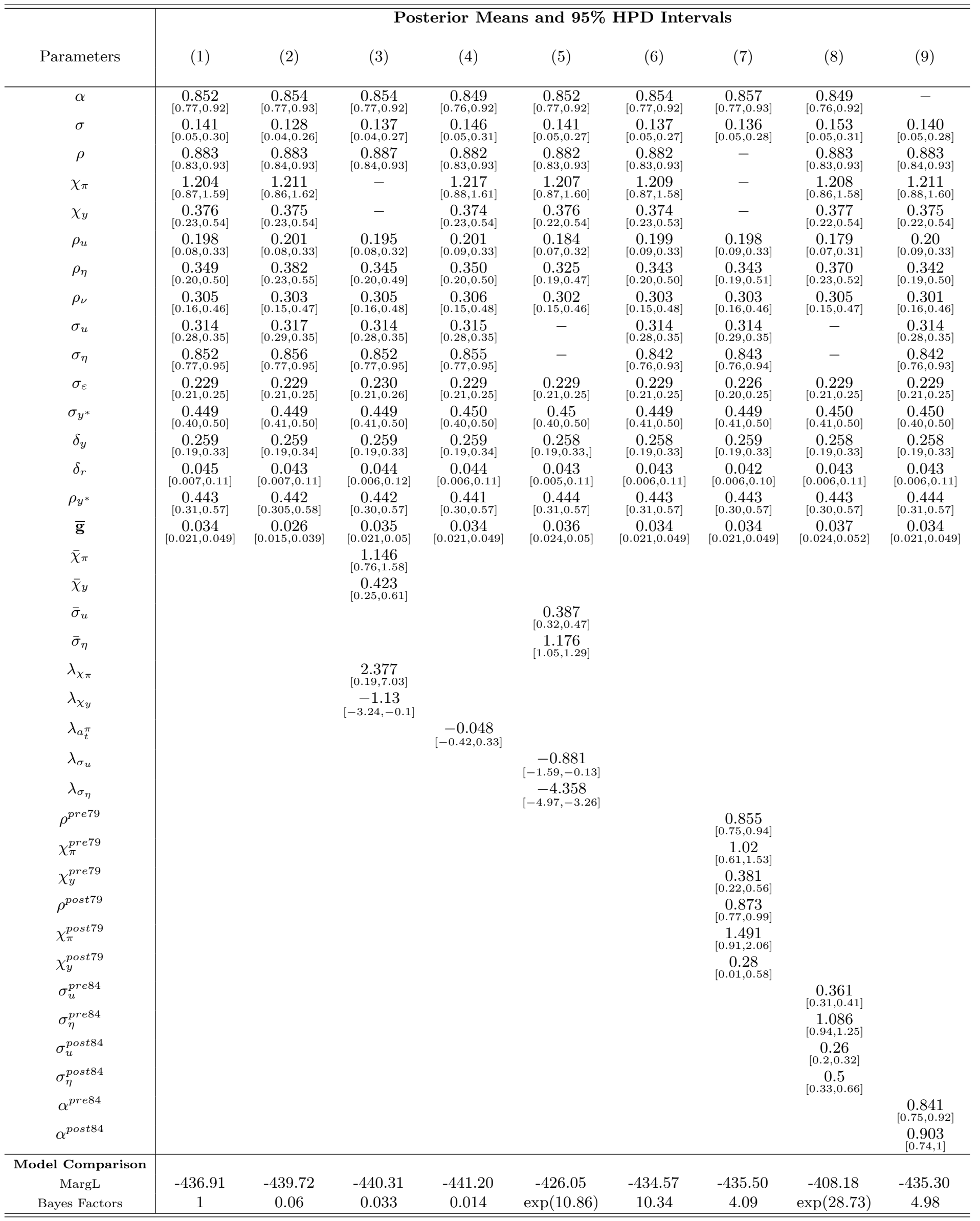


Table 2 - Empirical Results: Posterior Estimates. The main entries denote posterior mean estimates, while the numbers below in brackets denote $95 \%$ Highest Posterior Density (HPD) intervals.

(1): baseline open-economy specification.

(2): open-economy specification, in which the PLM includes global output.

(3): open-economy specification, in which the monetary policy coefficients vary with openness.

(4): open-economy specification, in which the perceived steady-state level of inflation depends on openness.

(5): open-economy specification, in which the standard deviations vary with openness.

(6): closed-economy specification.

(7): closed-economy specification, which allows for a structural break in the monetary policy rule coefficients.

(8): closed-economy specification, which allows for a structural break in the standard deviations of the shocks.

(9): closed-economy specification, which allows for a structural break in the slope of the Phillips curve. 


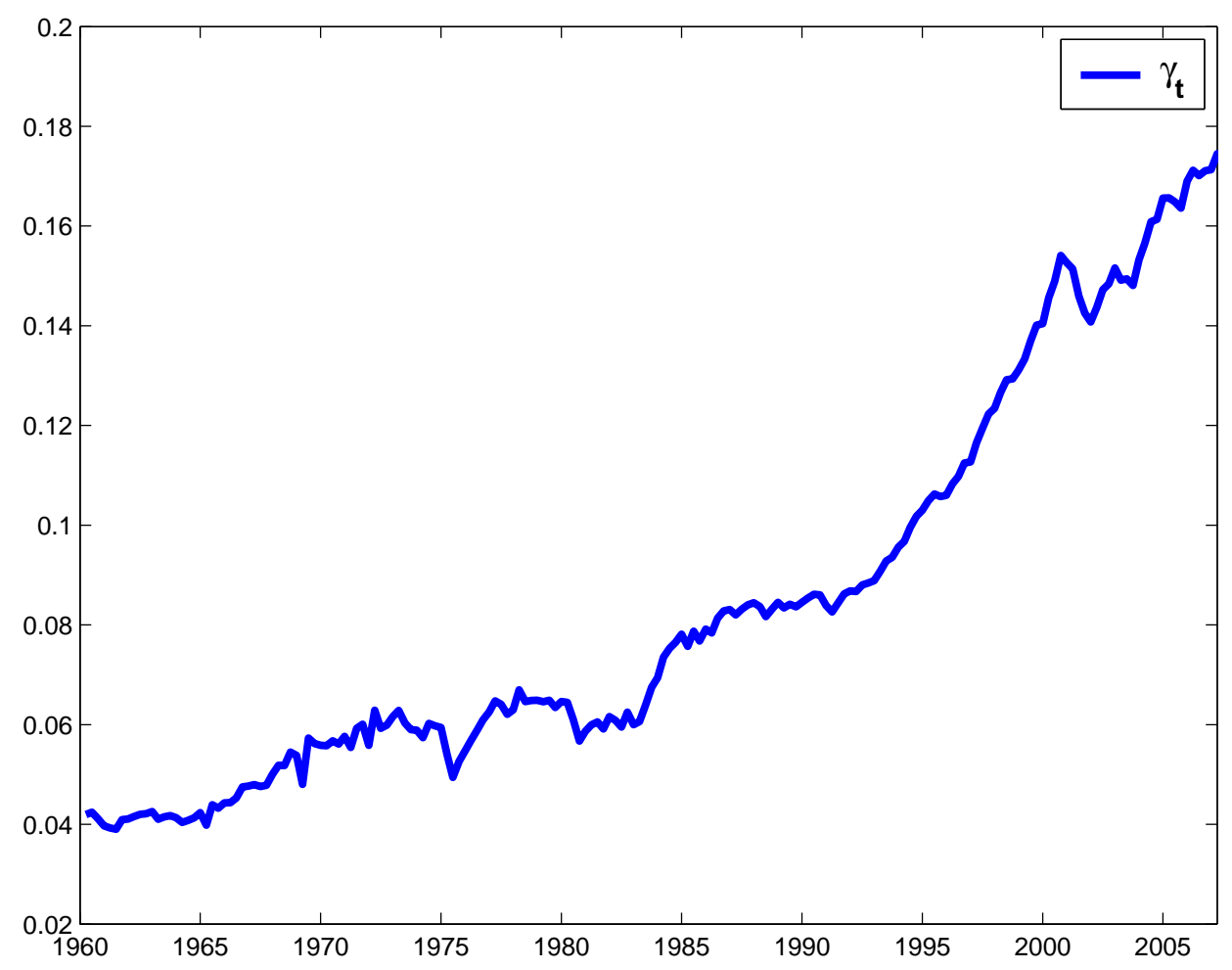

Figure 1. Evolution of $\gamma_{t}$, the openness parameter, over time.

Note: $\gamma_{t}$ is calculated as U.S. total real imports of goods and services as a fraction of U.S. real GDP over time. 
22

FABIO MILAN

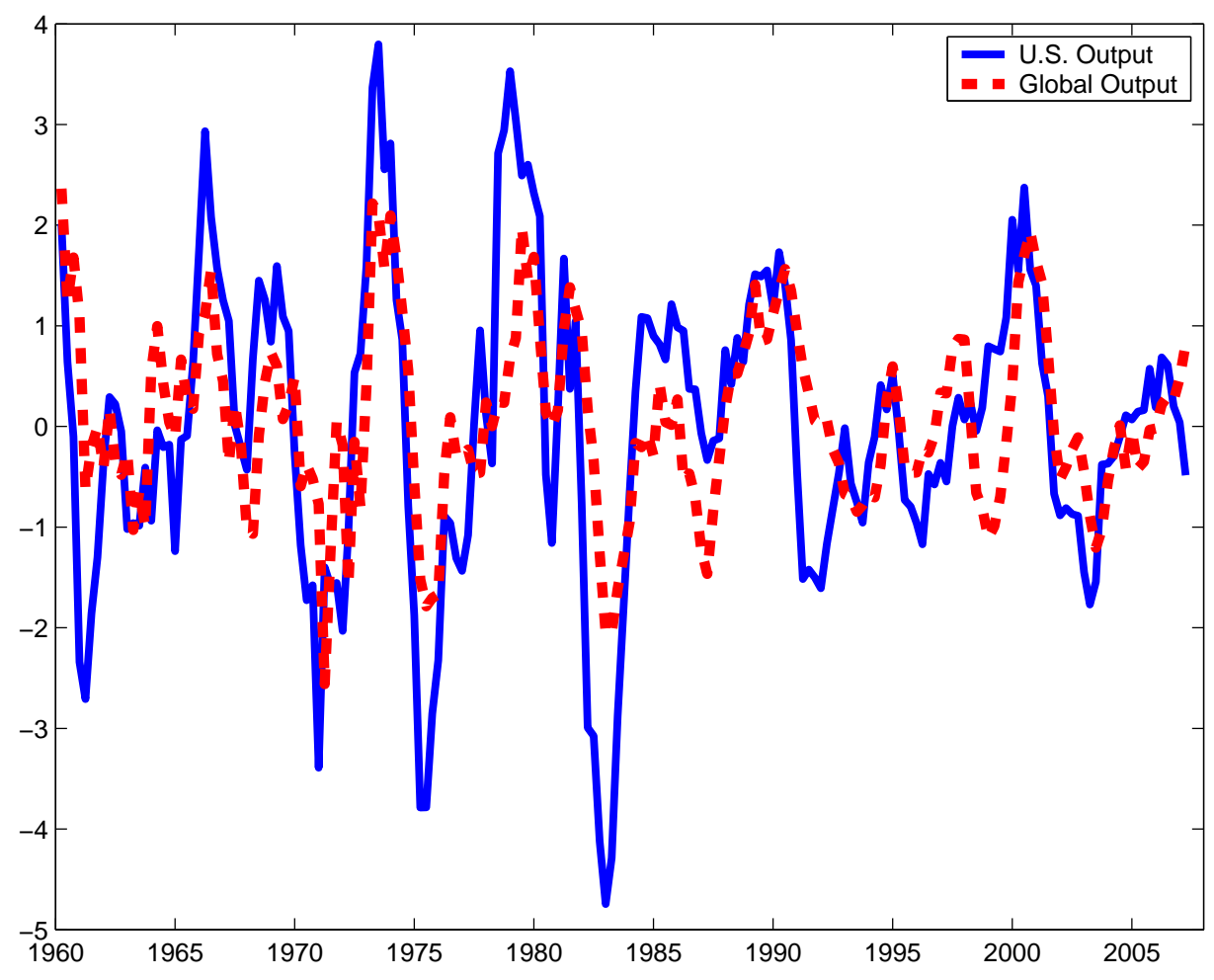

Figure 2. U.S. and "Global" Output series. 

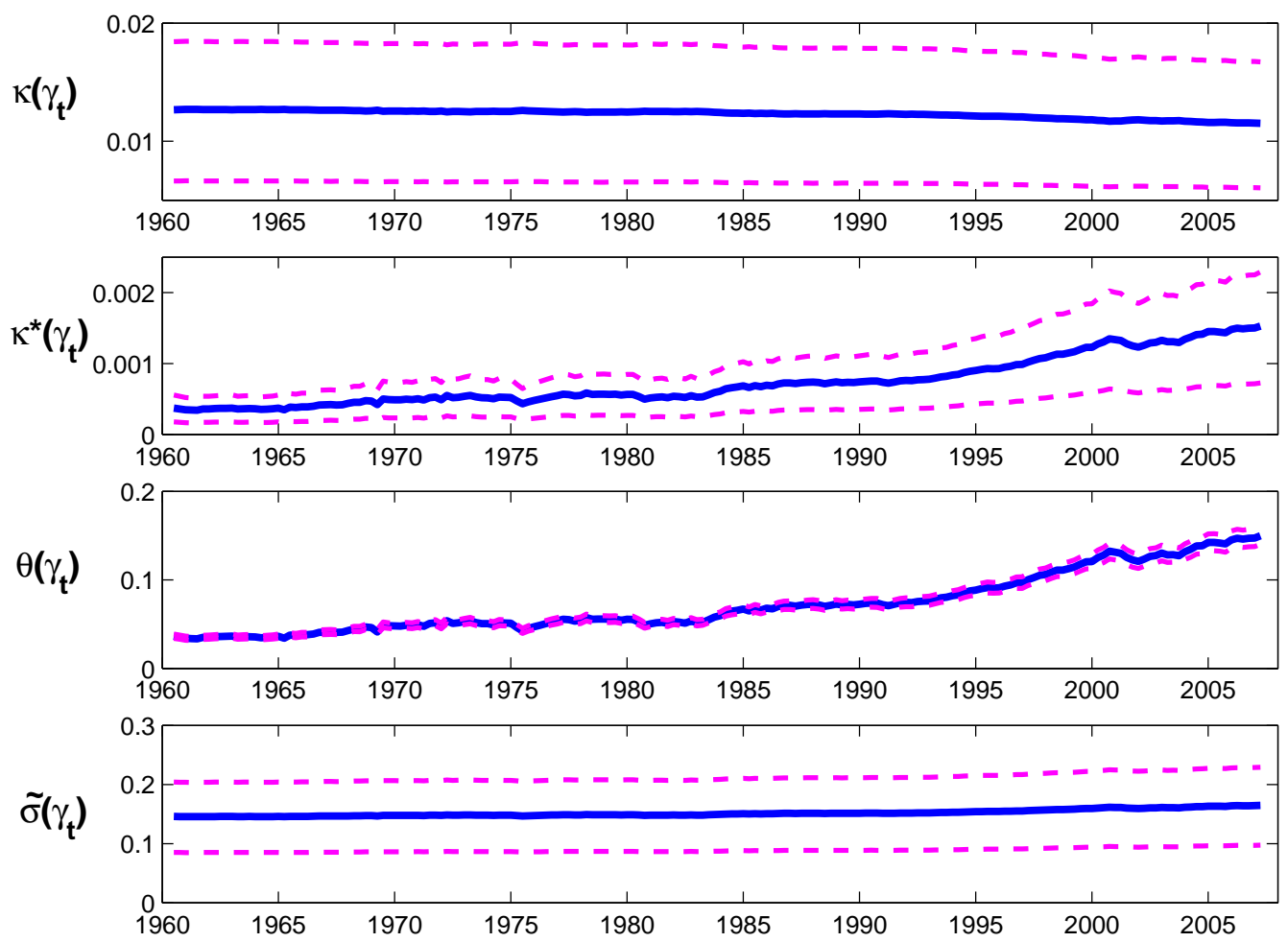

FIGURE 3. Evolution of the reduced-form coefficients that vary over time as a function of openness.

Note: The figure shows the mean of the time-varying reduced-form coefficients across MCMC draws, along with $17 \%$ and $83 \%$ percentiles (dashed lines). 

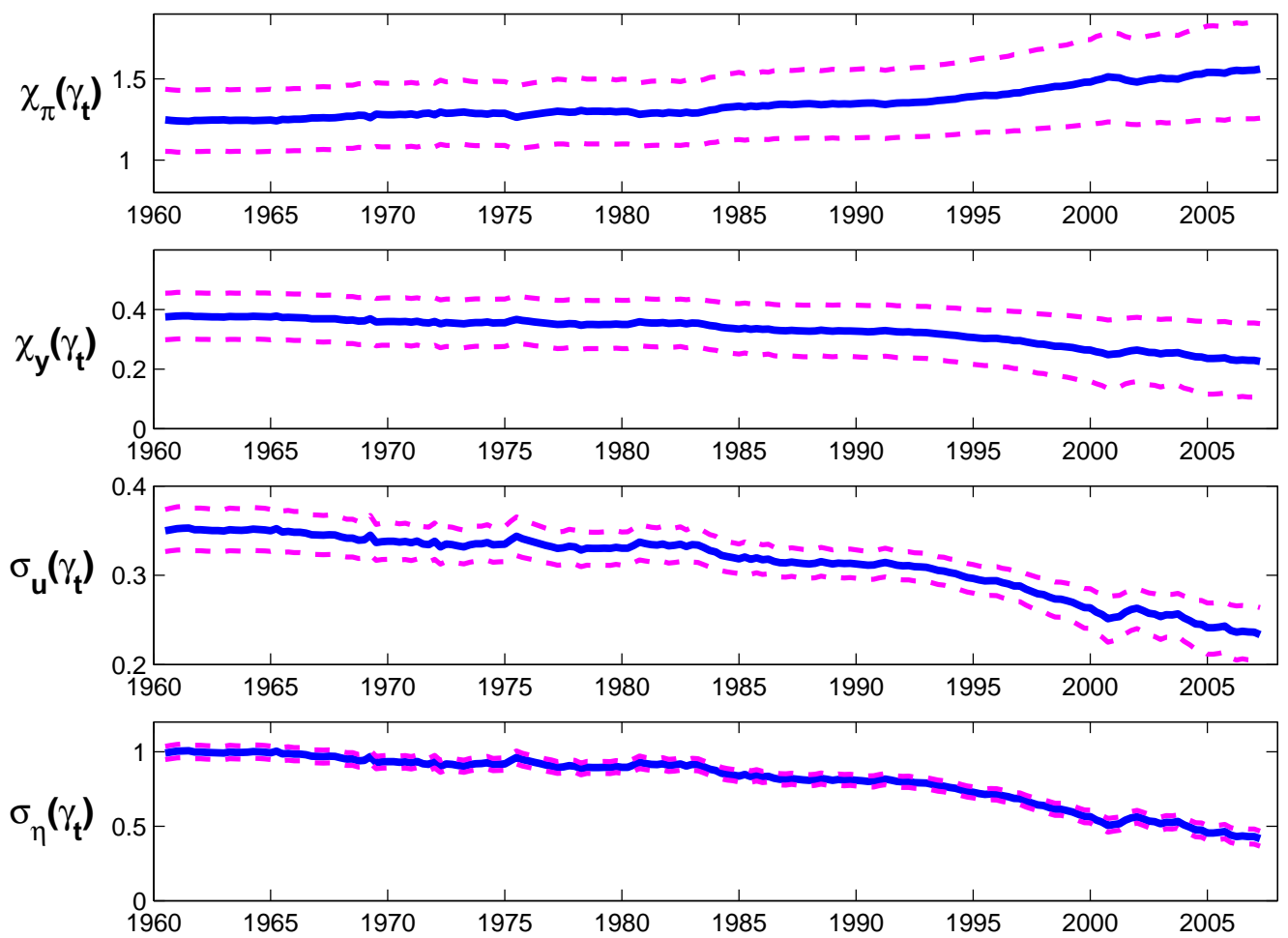

FiguRE 4. Evolution of reduced-form coefficients that depend on openness.

Note: The figure shows the mean of the time-varying monetary policy and standard deviation coefficients across MCMC draws, along with $17 \%$ and $83 \%$ percentiles (dashed lines). The monetary policy coefficients refer to column (3) and the standard deviations to column (5) in Table 2. 

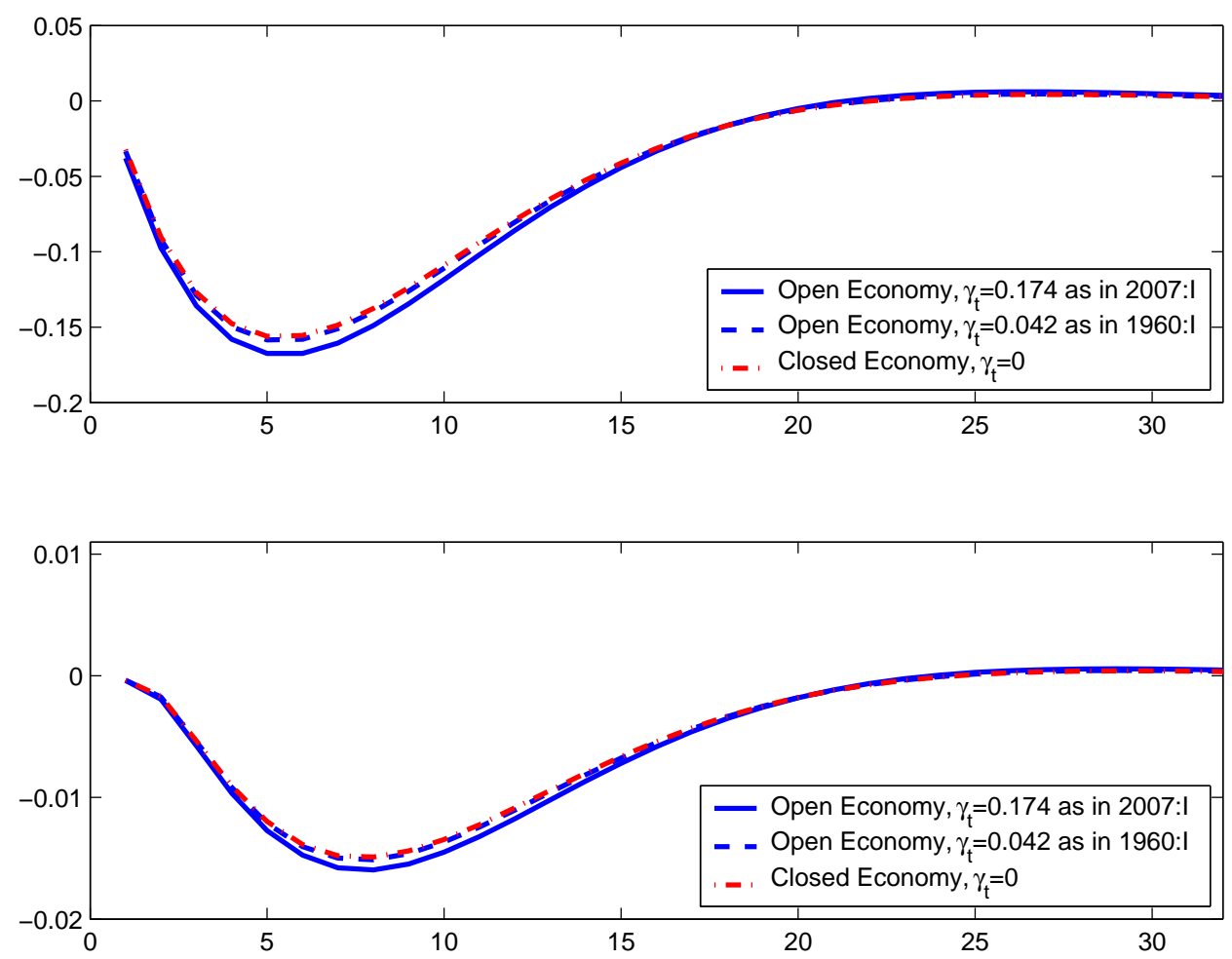

FiguRE 5. Impulse response functions of detrended output (upper plot) and inflation (lower plot) to a one-standard-deviation monetary policy shock.

Note: The figure shows the impulse responses to a monetary policy shock that occurs in 2007:I (that is, with the estimated coefficients in the agents' learning rule fixed at their value in 2007:I), for different degrees of openness of the U.S. economy: 1) the degree of openness that exists in 2007:I; 2) the degree of openness reduced to its 1960:I level; 3) the closed-economy case. 

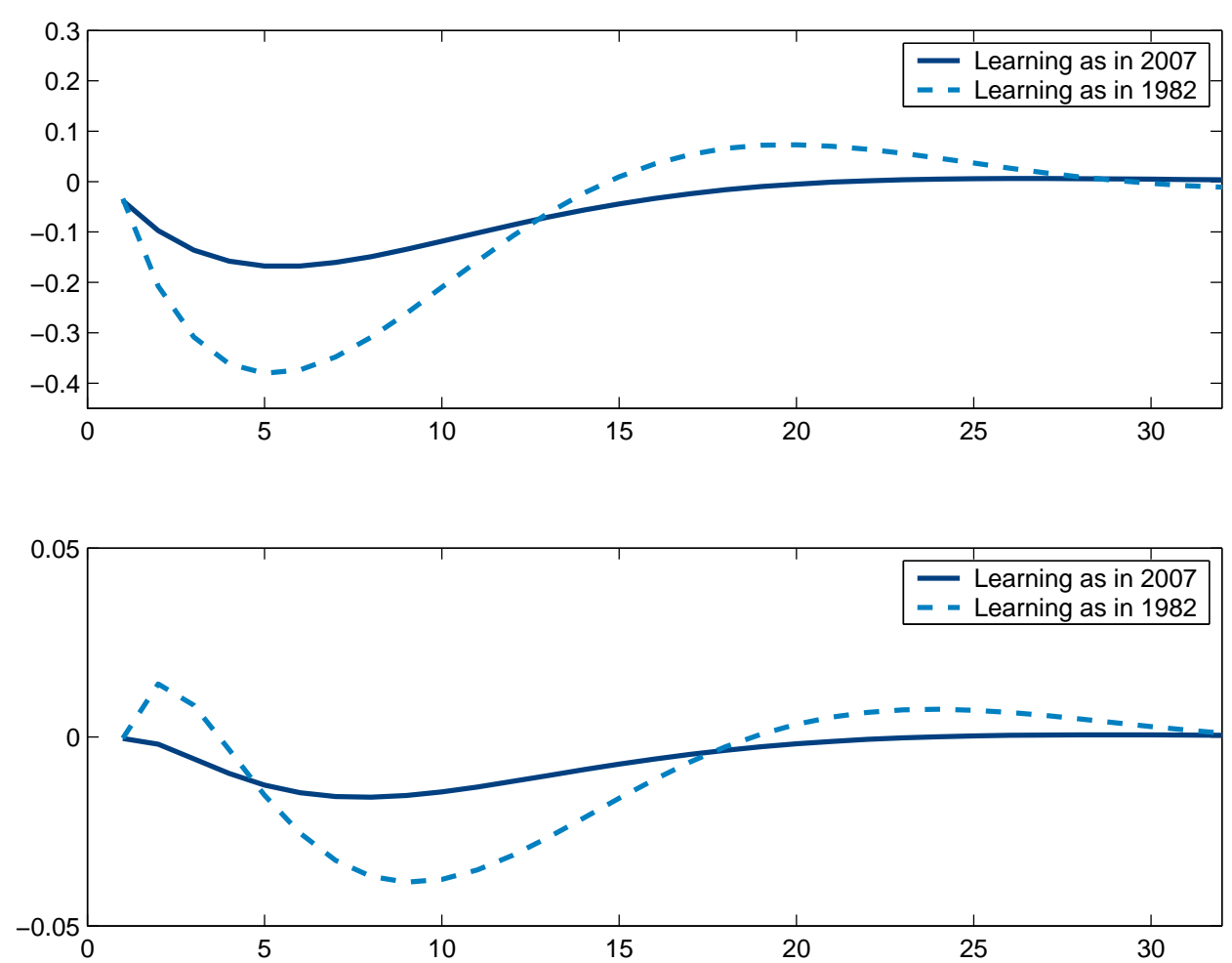

FiguRE 6. Impulse response functions of detrended output (upper plot) and inflation (lower plot) to a one-standard-deviation monetary policy shock.

Note: The figure shows the impulse responses to a monetary policy shock that occurs in 2007:I (i.e., with agents' learning fixed at its situation in 2007:I) or that would have occurred in 1982:1 (with agents' learning process brought back to its situation in 1982:I). 